\title{
Ideia de educação pública e cultivo das capacidades humanas ${ }^{1}$
}

The idea of public education and the cultivation of human capacities

Eine Idee ist nichts anderes, als der Begriff von einer Vollkommenheit, die sich in der Erfahrung noch nicht vorfindet. Z. E. die Idee einer vollkommen, nach Regeln der Gerechtigkeit regierten Republik!

Uma ideia não é outra coisa senão o conceito de uma perfeição que ainda não se encontra na experiência. Seria, por exemplo, a ideia de uma república perfeita regida segundo leis da justiça (KANT, 1998, p. 700-701). ${ }^{2}$

\author{
Cláudio Almir Dalbosco ${ }^{1}$ \\ Jelson Becker Salomão \\ Marcelo José Doro ${ }^{3}$
}

Resumo: O ensaio faz a defesa da educação pública, concebendo-a como esteio forte da república democrática. Investiga, na primeira parte, a ruptura entre filosofia política e pedagogia, entre teoria da democracia e teoria da formação humana e o quanto tal ruptura dificulta a reflexão sobre o crescimento mundial do neoconservadorismo. Na segunda parte, considerando o diagnóstico de que o avanço da perspectiva neoconservadora provoca a destruição da educação pública e considerando o quanto isso obstaculiza a consolidação cultural e moral da democracia, procura reconstruir alguns traços gerais da educação republicana esboçada por Kant em suas aulas Über Pädagogik. Concluí que a ideia kantiana de educação pública focada no cultivo de todas as capacidades humanas é o aspecto nuclear da formação do futuro cidadão, devendo, por isso, ser também a tarefa da escola pública atual.

Palavras-chave: Educação pública. Formação humana. Democracia.

\footnotetext{
${ }^{1}$ Agradecemos aos professores Hans-Georg Flickinger e Pedro Goergen pela leitura cuidadosa e pelas críticas e sugestões

${ }^{2}$ A tradução do alemão para o português desta e de todas as outras passagens de "Sobre a pedagogia" (Über Pädagogik) são de nossa responsabilidade.
} 
Abstract: This essay defends public education, conceiving it as the mainstay of the democratic republic. In the first part, the essay investigates the rupture between political philosophy and pedagogy, between the theory of democracy and the theory of human education and how much such a rupture hinders reflection on the worldwide growth of neoconservatism. In the second part, considering the diagnosis that the advance of the neoconservative perspective causes the destruction of public education and considering how much this hinders the cultural and moral consolidation of democracy, the essay reconstructs some general features of the republican education outlined by Kant in his Über Pädagogik classes. The essay concludes that the Kantian idea of public education focused on cultivating all human capacities is the core aspect of the education of future citizens, and should therefore also be the task of the current public school.

Keywords: Public education. Human education. Democracy.

${ }^{1}$ Universidade de Passo Fundo | Programa de Pós-Graduação em Educação | Passo Fundo | RS | Brasil. Contato: vcdalbosco@hotmail.com. ORCID: http://orcid.org/0000-0003-3408-2975

${ }^{2}$ Universidade de Passo Fundo | Curso de Filosofia | Passo Fundo | RS | Brasil. Contato: jelson@upf.br. ORCID: https://orcid.org/0000-0001-6461-3285

${ }^{3}$ Universidade de Passo Fundo | Curso de Filosofia | Passo Fundo | RS | Brasil. Contato: marcelodoro@upf.br. ORCID: https://orcid.org/0000-0001-9765-1958

- Recebido em: 3 de dezembro de 2019

- Aprovado em: 29 de junho de 2020

DOI: http://dx.doi.org/10.1590/S1414-40772021000100009

Este é um artigo publicado em acesso aberto sob uma licença Creative Commons

https://creativecommons.org/licenses/by-nc/4.0/ 


\section{Introdução}

Constata-se, na atualidade, o avanço mundial, especialmente brasileiro, do neoconservadorismo, o qual provoca o desaparecimento progressivo das humanidades, pondo em risco a democracia. O neoconservadorismo caracteriza-se, entre outros aspectos, pelo ataque às instituições democráticas e às formas cooperativas de vida social, bem como pelo desrespeito às liberdades individuais. Como visão de mundo, representa uma maneira dogmática e fechada de pensar; como postura política, sustenta-se na hierarquia autoritária e disciplinadora; como projeto social, fomenta a desigualdade, aumentando a pobreza e a injustiça social; e, por fim, como projeto educacional, contrapõe-se à ideia de que a educação organizada pelo Estado é decisiva para as formas plurais e democráticas de vida. Em um contexto sombrio como este, torna-se urgente intensificar a reflexão sobre o sentido e a finalidade da educação pública.

Considerando isso, põe-se a necessidade de resgatar a aliança iluminista estreita entre teoria da democracia e teoria educacional, mais precisamente, a ideia de que a educação organizada pelo Estado é condição sine qua non da vida democrática e, por consequência, de maior justiça social entre os seres humanos. Isso exige, de um ponto de vista sistemático mais amplo, retomar o nexo entre filosofia política e formação humana. Para autores modernos, como Jean-Jacques Rousseau e Immanuel Kant, a organização republicana da sociedade dependia fundamentalmente de processos educacionais que deveriam começar já na infância, descortinando para a criança experiências formativas de cooperação e solidariedade social, que seriam indispensáveis para que ela, quando adulta, pudesse fazer uso democrático de seu discernimento na esfera pública. Em síntese, a educação pública, concebida como espaço voltado para a formação da capacidade de julgar por conta própria, é indispensável, na concepção destes dois autores, para construir a república democrática de iguais entre iguais.

Portanto, retomar o diálogo entre filosofia política e formação humana ainda é um dos principais antídotos contra a concepção neoconservadora e a negação, que ela representa, da capacidade humana de pensar por conta própria e do exercício autônomo de experiências democráticas. O neoconservadorismo, sustentando-se pelo pensamento hierárquico autoritário e excludente, aumenta ainda mais a injustiça entre os seres humanos. Uma vez que ele se torna indiferente às questões sociais mais agudas, como pobreza e fome, apagando-as de sua agenda governamental, então, a crítica ao seu avanço pode transformar-se simultaneamente na defesa da própria justiça social.

O presente ensaio insere-se, grosso modo, no âmbito desta problemática. Dividido em duas partes, trata, na primeira, com base em Axel Honneth (2013), das razões que conduziram 
ao distanciamento entre filosofia política e formação humana, entre teoria da democracia e teoria da educação. Na segunda parte, reconstrói a defesa que Immanuel Kant faz em Über Pädagogik ("Sobre a pedagogia") da educação pública, vinculando-a, sob forte impacto da obra "Emilio" de Jean-Jacques Rousseau, à educação moral. Por fim, em forma de conclusão, faz breve balanço crítico da ideia kantiana de educação pública, procurando referir alguns aspectos de sua possível atualidade.

\section{A ruptura perigosa de um diálogo promissor}

$\mathrm{Na}$ tradição cultural ocidental, o pensamento sobre a política nasce com a própria filosofia. Nesse sentido, a obra "A república” é um texto paradigmático, no qual Platão (1987) pensa a organização política da sociedade, atribuindo papel central à educação dos cidadãos na vida da polis. O filósofo grego tinha consciência de que a ação humana de acordo com o estado ideal exigia longo processo formativo que deveria envolver a educação de todas as capacidades humanas e não só daquelas estritamente políticas ou econômicas, das quais dependia a sobrevivência. Desse modo, o difícil discernimento sobre o que é a justiça e a busca constante e inesgotável para torná-la efetiva na ação entre os seres humanos deveria vir embasada na ideia de uma formação humana geral (Paidéia), que pudesse dar conta das questões relativas tanto ao

corpo quanto à alma dos cidadãos atenienses. É justamente por isso que em "A república" a educação do intelecto vem ancorada na educação física, visando ambas o desenvolvimento equilibrado das dimensões sensíveis, afetivas e intelectuais do educando. O Estado deveria desempenhar, segundo Platão, papel importante para organizar as condições de uma educação adequada dos cidadãos e, neste contexto, pensar tanto o papel do Estado como tais condições educacionais era obrigação do próprio pensamento filosófico sobre a política. Desse modo, o problema filosófico central sobre qual deveria ser a melhor coletividade política frente à condição humana estava profundamente imbricado com os conteúdos e métodos da educação.

Esse laço estreito pensado filosoficamente por Platão entre política e educação ganha contornos ainda mais definidos na Modernidade com o ambicioso, embora ainda assistemático, projeto de educação levado a cabo por Jean-Jacques Rousseau em sua obra prima "Emílio ou da educação". Certamente, não foi apenas por mera veneração à tradição que o genebrino considerou "A república" o melhor tratado de educação já produzido pela humanidade (ROUSSEAU, 1992). Se a referida obra de Rousseau não pode ser considerada, estritamente, um tratado educacional em defesa da educação escolar pública e, por isso, não se ocupa explicitamente de problemas de conteúdo e método escolares, pensa, contudo, em 
profundidade, a imbricação estreita entre autogoverno infantil e atuação adulta, moral e política, na esfera pública. Do ponto de vista arquitetônico, os três primeiros livros da referida obra, que esboçam os traços gerais da educação natural, são a propedêutica indispensável da educação moral (livro quarto) e política (livro quinto) do aluno fictício, visando prepará-lo adequadamente para a vida cidadã na república de iguais entre iguais (DALBOSCO, 2016). Sendo assim, Rousseau considera indispensável a defesa da educação pública, não necessariamente escolar, para a sustentação cultural e moral da república democrática.

Seguindo de perto as pegadas de Rousseau, o filósofo alemão Immanuel Kant (1998) reafirma o nexo entre educação infantil e ação moral adulta na esfera pública. Suas aulas "Sobre a pedagogia", proferidas ao longo de vários semestres na Universidade Albertina de Königsberg, oferecem uma ideia precisa do quanto a educação pública era importante para garantir a república democrática. Com forte inspiração em Rousseau, Kant atribui tarefa inicialmente negativa à educação infantil, concebendo como papel indispensável da instrução pública o trabalho pedagogicamente cuidadoso sobre o egoísmo infantil. Por isso, antes de querer inculcar na criança princípios morais abstratos, que ela não poderia entender e precisamente por isso não saberia usar, tanto a família como a escola deveriam oportunizar a ela experiências formativas que a acostumassem a viver mediante pequenas regras. Pois, o exercício constante de observação formativa de tais regras era entendida como indispensável para a convivência democrática futura no ambiente adulto: agir mediante regras menores seria um pressuposto necessário para a vida moral adulta de sentir-se livremente obrigada a agir de acordo com o ordenamento da lei moral maior, a qual exige tomar sempre a humanidade como fim e jamais como meio. Em síntese, o laço entre educação infantil e ação moral adulta na esfera política e o dever da escola pública em formá-lo constituía uma ideia central não só do pensamento político educacional de Kant, mas também da mais alta tradição do Iluminismo moderno.

Essa brevíssima referência aos clássicos da filosofia política e educacional, embora vivendo tais autores em momentos históricos e políticos distintos e bem diferentes entre si, como é o caso de Platão em relação a Rousseau e Kant, já é suficiente para mostrar o quanto, tanto na Antiguidade como na Modernidade, o vínculo entre filosofia, política e educação era indispensável para justificar formas de vida democráticas. Se isso é assim, podemos perguntar por que na contemporaneidade, ou seja, no mundo filosófico atual, este vínculo tornou-se cada vez mais tênue? O que de fato aconteceu para que progressivamente a filosofia política contemporânea deixasse de se interessar por questões educacionais? 
Axel Honneth profere, em 12 de março de 2012, na cidade de Osnabrück/Alemanha, a famosa conferência intitulada "Erziehung und demokratische Öffentlichkeit. Ein vernachlässigtes Kapitel der politischen Philosophie" ("Educação e esfera pública democrática. Um capítulo negligenciado da filosofia política"), no âmbito do $23^{\circ}$ Congresso da Deutsche Gesellschaft für Erziehungswissenschaft (Sociedade Alemã de Ciência da Educação). Na referida conferencia, Honneth, um dos principais representantes vivos da tradição da teoria crítica, analisa dois fatores que explicam o esquecimento de questões educacionais por parte da filosofia política. Sua análise insere-se nitidamente na tradição republicana moderna, segundo a qual a democracia precisa ter sustentação cultural e moral, pois, sem tal sustentação, a própria república não sobreviveria. É nesse sentido, então, que a justificação da república democrática, concebida como problema nuclear da filosofia política moderna, transforma-se simultaneamente em grande empreitada educacional, ou seja, em formação cultural e moral da vontade democrática. Tal entrelaçamento conduz Honneth, por um lado, a colocar Jean-Jacques Rousseau, Immanuel Kant, Émile Durkheim e John Dewey entre os principais defensores da ideia cultural e moral da democracia e, por outro, a criticar o afastamento perigoso da filosofia política contemporânea em relação às questões educacionais.

Podemos pensar, à primeira vista, que o fator determinante que gerou tal esquecimento é a especialização crescente assumida pelos diferentes domínios do conhecimento humano. Se a teoria da sociedade (sociologia) se tornou, no século XIX, cada vez mais independente da filosofia, no século $\mathrm{XX}$, de maneira muito semelhante, as questões educacionais foram delegadas, mais e mais, à pedagogia científica. Ou seja, a diferenciação progressiva das disciplinas avulsas teria sido, então, o principal motivo que levou a filosofia política a se distanciar da questão da organização estatal da educação. Independentemente de ser ou não este o primeiro fator de tal distanciamento, a questão é que a pedagogia científica (ciências da educação), ao assumir a dianteira da investigação e planejamento do processo pedagógico escolar, deixou-se enredar facilmente pelo mito da neutralidade científica e, distanciando-se conscientemente da longa tradição da filosofia prática, enfraqueceu a dimensão ético-política da educação. ${ }^{3}$ Torna-se exemplar, nesse sentido, o fato de que a disputa sobre o positivismo na sociologia alemã também tenha alcançado imediatamente o domínio da pedagogia, reunindo,

\footnotetext{
${ }^{3}$ No contexto da filosofia da educação alemã contemporânea, Wolfdietrich Schmied-Kowarzik (2003) é um dos principais defensores do vínculo estreito entre filosofia prática e pedagogia. Ver, nas referências, indicação de obra do autor sobre o tema.
} 
de um lado, defensores da neutralidade pedagógica e, de outro, aqueles que ainda insistiam na raiz prática (ético e política) da formação humana. ${ }^{4}$

Contudo, mesmo que o avanço da pedagogia científica tenha provocado, à sua própria maneira, o esquecimento da dimensão ética e política da educação, ela não é, segundo Honneth, o primeiro grande fator impulsionador do distanciamento da filosofia política em relação às questões propriamente educacionais. Tal fator precisa ser encontrado em um nível conceitual mais profundo, referindo-se à "definição e exploração da abrangência em que a democracia pode influir sobre si mesma" (HONNETH, 2013, p. 549). Mas o que Honneth tem em mente quando fala desta influência da democracia sobre si mesma? Ele está pensando, certamente, naquelas forças teóricas neoconservadoras que apregoam a incapacidade das instituições do Estado democrático de direito, entre elas principalmente a educação escolar, de se constituir como força autogeradora de coletividades democráticas. Ou seja, segundo tais forças, a escola, assim como outras instituições sociais, torna-se impotente para transformar as condições de vida da democracia e formar o substrato cultural e moral indispensável à sua sustentação. Emerge aqui, nitidamente, nesse diagnóstico, a ruptura entre democracia e educação, deixandose explicar por duas fontes teóricas distintas, as quais têm influenciado, ao longo das últimas duas décadas, o debate sobre a concepção da própria democracia. Analisemos, com mais vagar, estas duas forças teóricas, uma vez que sua compreensão é decisiva para entendermos o ataque sem trégua desferido na atualidade contra a educação pública.

A primeira fonte teórica provém do campo da filosofia do direito e ficou conhecida como a tese de Böckenförde (2006) $)^{5}$, a qual diz que a democracia depende, para sua manutenção, de componentes morais e culturais anteriores a ela mesma. Isso quer dizer, na prática, que o Estado democrático de direito possui um espaço muito pequeno para a formação de sua base moral e cultural e que a maior parte de tal formação se origina de "comunidades consolidadas com orientações éticas substanciais e até religiosas” (HONNETH, 2013, p. 550). Se tal diagnóstico procede, ele aponta então para um limite grave do Estado democrático de direito, na medida que revela sua incapacidade de promover sua própria sustentação moral e cultural, precisando ir buscá-la fora de suas próprias instituições diretamente responsáveis por isso. A conclusão plausível que se pode tirar da tese de Böckenförde, a qual atinge frontalmente

\footnotetext{
${ }^{4}$ A coletânea "Der Positivismusstreit in der deutschen Erziehungswissenschaft" ("A disputa sobre o positivismo na ciência da educação alemã”), organizada por Wilhelm Büttemeyer e Bernhard Möller (1979), documenta bem este debate.

${ }^{5}$ Honneth refere-se aqui pontualmente ao trabalho "Freiheit und Recht, Freiheit und Staat" ("Liberdade e direito, liberdade e Estado”), de Ernst-Wolfgang Böckenförde.
} 
a educação pública, é que os processos educacionais organizados pelo Estado são incapazes de oferecer sustentação cultural e moral ao Estado democrático de direito. Isso significa dizer, sob a ótica estritamente educacional, que a escola e pré-escola não conseguem formar valores e comportamentos essenciais ao fortalecimento do espírito democrático. Ou seja, a capacidade de tolerância, a disposição de se colocar no lugar do outro e a orientação para o bem comum não são mais resultados do processo de ensino, mas sim de comunidades pré-políticas e, portanto, se desenvolvem fora da esfera pública tradicional, até então representada classicamente pela escola pública. Em síntese, a expansão da tese de Böckenförde para além de seu próprio circuito teórico permite a seguinte conclusão, devastadora da educação pública: “todos os esforços estatais de organização de uma educação democrática são em vão porque não podem gerar as virtudes morais que são vitalmente necessárias para a subsistência de democracias" (HONNETH, 2013, p. 550). Em resumo, essa primeira fonte teórica conduz ao enfraquecimento da educação pública, delegando a comunidades pré-políticas a tarefa de oferecer a substância cultural e moral indispensável ao laço social solidário.

É impressionante notar o quanto a tese de Böckenförde, que por outras forças políticas é expandida muito além de suas próprias intenções teóricas iniciais, também pode servir como elucidação teórica do desmonte ideológico e político atualmente em curso na educação pública, sobretudo no continente latino-americano. Especialmente no cenário brasileiro, ataca-se ideologicamente a educação pública por meio da conjugação de um duplo interesse aparentemente contraditório: o interesse econômico neoliberal, que há muito tempo percebeu, mundo afora, o quanto a educação pode tornar-se um "produto" altamente lucrativo, e, ao mesmo tempo, o interesse ideológico religioso de colocar a escola sob domínio de igrejas visando a assegurar a concepção de mundo ultraconservadora, decididamente contrária a formas de vida plurais e democráticas. O que lá, no âmbito da tese de Böckenförde, ainda acontecia em nome da formação de valores culturais e morais de certa forma democráticos, aqui, no espaço da política educacional bolsonarista, implica o desmanche da educação pública em nome da defesa ideológica escancarada de valores culturais, morais e religiosos, profundamente neoconservadores. Desse modo, o ultraconservadorismo ideológico da comunidade moral bolsonarista, ao desmerecer a educação pública, agride frontalmente a cultura democrática que sustenta o Estado democrático de direito. Nesse sentido, atualmente, no Brasil, assim como historicamente também já ocorrera em outros países, fazer a firme defesa da educação pública é vital para garantir a difícil, mas imprescindível, formação da vontade democrática.

A segunda fonte teórica que conduziu à ruptura entre teoria da democracia e teoria da educação vem de outra perspectiva normativa, ainda mais forte do que a tese de Böckenförde, 
a saber, da interpretação restritiva do imperativo da neutralidade do Estado, a qual formula, com muito mais energia, o postulado de que o ensino escolar público não é mais a fonte de expressão dos princípios de formação da vontade democrática. Antes de tudo, é preciso não confundir a defesa neoconservadora da neutralidade do Estado com a defesa da neutralidade moral e religiosa do Estado, como é feito, entre outros, por Jürgen Habermas, para assegurar direitos iguais de expressão do crescente pluralismo de culturas étnicas e religiosas no espaço das sociedades complexas atuais (HABERMAS, 2007). Tal defesa habermasiana mostra-se razoável, pois se o Estado procurasse impedir qualquer manifestação religiosa ou tomasse partido previamente por uma ou outra religião, transformando-a exclusivamente em religião oficial, então excluiria imediatamente as outras ou, no mínimo, trataria desigualmente as religiões ao demonstrar preferência por alguma delas. Contrariamente a essa perspectiva, Habermas conduz sua análise de maneira a evitar, por um lado, a exclusão das religiões em nome simplesmente da secularização do Estado e, por outro, menos ainda, de fazer o Estado democrático de direito ceder às pressões retrógradas e conservadoras de certas cosmovisões religiosas. Nesse contexto, ele vê como condição altamente formativa a convivência entre cidadãos seculares e comunidades religiosas, uma vez que o "etos democrático de cidadãos do Estado (na interpretação por mim sugerida) só pode ser imputado simetricamente a todos os cidadãos se estes, tanto os seculares como os religiosos, passarem por processos de aprendizagem complementares" (HABERMAS, 2007, p. 158; grifo nosso). Em síntese, está claro, nessa citação, a necessidade de formação recíproca do etos democrático para todos os cidadãos, independentemente de possuírem ou não convicções religiosas. Sobretudo, quando as religiões oferecem aquele cimento de solidariedade indispensável para as formas cooperativas de vida, então elas se tornam força cultural e moral importante para a formação da vontade democrática.

Contudo, o esforço habermasiano não pode ser confundido de maneira alguma com a neutralidade do Estado concebida restritivamente porque ela não só encolhe inaceitavelmente a esfera democrática como, em decorrência disso, procura apagar o vínculo clássico entre educação pública e formação da vontade democrática. Se, no caso de Habermas, o princípio da neutralidade torna-se um princípio discursivo básico para assegurar direitos (FORST, 2010, p. 64), a defesa restritiva da neutralidade do Estado é empregada pelo neoconservadorismo atual para enfraquecer a escola pública e seu compromisso com a formação do etos democrático. Sob esta ótica, o princípio da neutralidade do Estado torna-se restritivo porque, em vez de assegurar direitos, tira-os, e faz isso, principalmente, em detrimento de quem mais necessita. Nesse contexto, a tentativa de enfraquecimento da escola pública ocorre movido por duplo interesse: 
em primeiro lugar, assumido geralmente pelos próprios governantes, de despolitizar a educação escolar; e, em segundo lugar, defendida principalmente pelos pais, coloca-se a reivindicação que a escola se concentre somente na função de promover a formação profissional de seus filhos. Honneth evidencia enfaticamente o lado desastroso de tudo isso: "por consequência, o imperativo da neutralidade do Estado é estendido até o ponto em que a própria ideia de educação democrática perde sua naturalidade normativa" (HONNETH, 2013, p. 552). Disso resultam, como fica claro, duas consequências danosas para a democracia, a saber, não é mais dever do Estado organizar a educação e não compete mais à escola a formação da vontade democrática.

Se voltarmos, mais uma vez, nosso olhar para o cenário brasileiro atual, podemos perceber imediatamente o quanto os interesses do governo e de certas famílias coincidem perfeitamente, no propósito da despolitização da escola pública e na redução do seu papel à mera profissionalização das novas gerações. Iniciativas como a da Escola Sem Partido e, sobretudo, do projeto Educação Domiciliar, que tramita na Câmara dos Deputados, são tomadas também com o propósito de mostrar a incompetência do Estado para organizar a educação, o que, de outra parte, busca assegurar somente às organizações civis, principalmente às associações de pais, o monopólio da educação profissional das novas gerações. Nesse contexto, não só o conteúdo e o método escolar perdem sua necessária independência, como os próprios professores se tornam reféns dos interesses das associações de país. Honneth sinaliza com agudeza crítica o que está precisamente em jogo nesta questão: "Neste sentido, o conflito em torno do sistema escolar estatal, independentemente dele dizer respeito à sua estruturação, aos currículos e aos métodos empregados, sempre é também uma luta pela viabilidade das democracias para o futuro" (HONNETH, 2013, p. 552). Ou seja, lutar atualmente, no Brasil, mas também no mundo, pela educação pública significa manter acesa a chama, para as gerações futuras, de formas plurais e democráticas de vida e, com isso, a perspectiva aberta de mais justiça social.

Em síntese, baseando-nos na interpretação de Honneth, reconstruímos duas fontes teóricas que explicam o distanciamento da filosofia política em relação às questões educacionais, mais precisamente, o desinteresse que a reflexão filosófica sobre a democracia manifestou progressivamente, sobretudo a partir da segunda metade do século XX, pela formação cultural e moral como pressuposto da própria sustentação de formas plurais e democráticas de vida. Contudo, essas valiosas indicações de Honneth ficariam incompletas, se não agregássemos a elas um outro fenômeno social, o qual não só bloqueia o diálogo entre filosofia política e educação, como também significa um ataque frontal à educação pública, talvez muito mais violento e destrutivo que as duas fontes teóricas acima citadas. Referimo- 
nos, aqui, mais precisamente, ao fenômeno da mercantilização crescente da educação, levado a cabo de maneira muito decidida pelo neoliberalismo contemporâneo. A educação formal, submetendo-se ao modelo do gerenciamento empresarial, distancia-se, em todas as suas dimensões, desde a pré-escola até o nível superior, cada vez mais das humanidades, curvandose irrestritamente ao princípio de lucratividade do mercado neoliberal. Como mostrou a filósofa americana Martha Nussbaum, em ensaio de tom nitidamente programático, o desaparecimento das humanidades dos currículos escolares põe em risco a existência da própria democracia (NUSSBAUM, 2017).

\section{Educação pública democrática}

No tópico anterior, elaboramos, com base na reconstrução livre da interpretação de Axel Honneth, o breve diagnóstico do distanciamento da filosofia política em relação às questões educacionais. $\mathrm{O}$ aspecto preocupante de tal distanciamento, assim podemos concluir agora, provisoriamente, é que ela, a filosofia política, acabou em grande parte fechando os olhos para o avanço político e social do neoconservadorismo e para o inerente risco de destruição da educação pública. A situação torna-se ainda mais dramática se considerarmos seriamente, como procuramos fazer acima, que tal destruição significa, ao mesmo tempo, o impedimento claro da manifestação de formas plurais e democráticas de vida. A destruição da educação pública reverte-se imediatamente no aniquilamento da escola pública, concebida desde a Modernidade como principal força formativa, cultural e moral, dos costumes democráticos.

Voltamo-nos, nesta segunda parte de nosso ensaio, para a defesa republicana que Immanuel Kant faz da educação pública, em suas aulas "Sobre a pedagogia" (KANT, 1998). Procuramos nos orientar, aqui, pela seguinte questão: Que ideia de educação pública aparece neste pequeno texto e em que sentido tal ideia torna-se indispensável à formação do futuro cidadão? Para enfrentá-la, ancoramo-nos na hipótese de que a república democrática depende de diferentes formas de autogoverno, as quais já precisam iniciar, também de maneira diversificada, na mais tenra idade do ser humano. Nesse contexto, compete à educação pública, organizada pelo Estado, assegurar as condições mínimas para que o autogoverno infantil se desenvolva progressivamente, considerando o estágio inicial de total dependência do bebê humano em relação ao adulto de sua referência mais próxima, até alcançar, já como cidadão adulto, a participação moral e política autônoma na esfera pública. Precisamente em razão disso, a educação pública assume primazia inquestionável em relação à educação doméstica, 
tornando, desse modo, a educação escolar propedêutica necessária para a moralização do ser humano.

Kant se ocupou de questões educacionais não só por exigências ministeriais oficiais impostas pelo governo prussiano de sua época, mas principalmente por razões sistemáticas. A pedagogia, compreendida como ampla investigação da formação humana geral e como estudo escolar em particular, significa, para ele, uma das formas mais expressivas de realização da razão prática, ou seja, do emprego moral e político da razão. Ela desempenha a tarefa de formação do ser humano para alcançar progressivamente sua moralização, condição indispensável da ação política no interior da república. Isso significa dizer, mais precisamente, que o cidadão virtuoso vivendo na república de iguais entre iguais depende de longo e interminável processo formativo. Sob esse aspecto, para Kant, exatamente na direção contrária às tendências neoconservadoras atuais, a educação pública desempenha papel insubstituível no sentido de assegurar o nexo entre democracia e formação humana e, com ele, experiências morais e políticas no âmbito da sociedade republicana.

Kant faz, na introdução de suas aulas "Sobre a pedagogia", a distinção entre educação doméstica (privada) e educação pública. A primeira, a educação doméstica, ocorre no ambiente familiar, sob orientação dos pais e, sobretudo, do professor privado (Hofmeister ou Hauslehrer) contratado pela família. Ele não vacila um só instante, mesmo considerando que aí a educação ocorre no âmbito familiar, em conceder autoridade maior ao professor (governante) em relação aos pais, quando o assunto diz respeito ao conteúdo e ao método educacionais. Portanto, para que ocorra uma boa educação doméstica, os educandos (filhos) precisam estar sob a autoridade pedagógica do governante. O pensador de Königsberg procede assim porque pressupunha que o professor privado tivesse domínio da cultura geral (Bildung), o que o habilitaria a ir além do provincialismo e da parcialidade familiar, tendo, assim, muito mais condições intelectuais de despertar aos poucos no educando o espírito cosmopolita necessário à formação cidadã. Desse modo, uma mente aberta, instruída criticamente sobre o que estava acontecendo em seu entorno, capaz de julgar a mesma coisa sob diferentes pontos de vista e de saber se relacionar de maneira razoável com opiniões diferentes seria o resultado característico de uma tal formação cosmopolita que os pais, na ânsia de querer assegurar o futuro profissional de seus filhos, seriam incapazes de proporcionar, opondo até mesmo, em muitos casos, ferrenhas resistências. Não custa lembrar, nesse sentido, que o próprio Kant exerceu durante vários anos, em três diferentes casas de família, a função de Hauslehrer (tutor particular), antes de se tornar professor universitário. Inclusive, nessa condição, como Hauslehrer, soube aproveitar muito bem o tempo disponível para se aprofundar nos estudos e preparar material para seu escrito de habilitação, 
requisito oficial para postular carreira acadêmica, ou seja, para assegurar seu posterior ingresso, como professor, na universidade (VORLÄNDER, 2003, p. 63-76).

A educação pública, por sua vez, estende-se muito além do ambiente familiar, encontrando na escola seu lugar de realização. Kant, embora não se ocupe sistematicamente com a educação escolar e, por isso, não problematize questões relacionadas nem ao currículo e nem aos métodos de ensino, não levanta dúvida quanto ao seu papel formativo em termos dos ideais republicanos. Mais precisamente, concebe a escola como locus clássico da formação da vontade democrática voltada para o respeito das leis que os cidadãos dão a si mesmos e que os tornam capazes de viver bem, respeitando-se uns aos outros, sob o mesmo teto da sociedade republicana. Na referida introdução às aulas "Sobre a pedagogia", Kant é explícito ao atribuir dupla função à educação pública: a) de possibilitar ao educando a descoberta da medida de suas próprias forças e b) de lhe propiciar o conhecimento e o respeito sobre os limites que o direito dos demais lhe impõe. Encontram-se, aqui, mutuamente implicados, os dois polos do processo tensional que constitui o núcleo da socialização moral humana: do lado do indivíduo, trata-se não só de descobrir quais são suas capacidades, mas também de saber qual é o melhor uso que pode fazer delas, tomando consciência, ou seja, aprendendo os limites de suas próprias capacidades. É por isso que a noção de medida se torna central nesse ponto, indicando a busca que o educando precisa empreender para encontrar, do ponto de vista moral e político, o seu lugar mais adequado no mundo. Do lado da sociedade, uma vez que a questão gira em torno do direito dos outros, trata-se de conhece-lo e respeitá-lo. Desse modo, respeito por si mesmo e respeito pelos outros constituem duas faces da mesma moeda, indispensáveis ao exercício da cidadania democrática. Ao desempenhar essa dupla função, a "educação pública oferece a melhor imagem do futuro cidadão (des künftigen Bürgers)" (KANT, 1998, p. 712).

O passo nuclear de "Sobre a pedagogia" é dado quando Kant alia sua defesa da educação pública com o cultivo em conjunto de todas as forças, ou seja, de todas as capacidades do ser humano (educando). ${ }^{6}$ Em uma passagem preciosa de suas aulas ele afirma: "A principal regra é essa: não cultivar isoladamente nenhuma capacidade de ânimo (Gemütskraft) por si mesma, mas sim uma em relação às outras, como a imaginação (Einbildungskraft) a serviço do entendimento (Verstand)" (KANT, 1998, p. 731; grifo nosso). Este princípio pedagógico antecipa de maneira clara o ideal da Bildung neohumanista subsequente, encabeçado por

\footnotetext{
${ }^{6}$ Ao traduzirmos Kraft (força) por capacidade (Fähigkeit) não estamos cometendo equívoco, pois o próprio Kant usa frequentemente essa última expressão. Contudo, nossa ênfase nessa tradução deve-se ao fato de interpretarmos Kant como teórico moderno das capacidades humanas, que as coloca, como procuramos mostrar neste ensaio, na base de sua ideia de educação pública voltada à formação da cidadania democrática.
} 
Wilhelm von Humboldt e Johann Friedrich Herbart, os quais colocam o referido ideal na base da grande reforma universitária alemã que promoveram, no século XIX (TENORTH, 2010). Há dois aspectos relacionados à passagem acima que merecem destaque especial, considerando os propósitos de nosso ensaio: primeiro, Kant argumenta que a educação pública que almeja a formação cidadã para a vida republicana precisa se concentrar no cultivo das capacidades humanas superiores, com destaque especial para entendimento (Verstand), razão (Vernunft) e imaginação (Einbildungskraft). Em segundo lugar, o filósofo sustenta que não se deve estabelecer hierarquia entre as capacidades superiores e que tampouco estas devem ser priorizadas em prejuízo ou exclusão das capacidades inferiores, como a memória (Gedächtnis), por exemplo.

Portanto, e esta é a tese central de nossa interpretação deste pequeno texto de Kant, o núcleo da educação pública voltada à formação do futuro cidadão (Bildung des künftigen Bürgers) repousa no cultivo de todas as capacidades do educando. Ora, sendo assim, como deve ocorrer tal cultivo? Para o momento, é suficiente referirmos a justificação que Kant oferece para o cultivo das três capacidades superiores, ou seja, do entendimento, da razão e da imaginação. Essas três capacidades referem-se, grosso modo, aos três empregos canônicos, atribuídos por Kant à razão humana, ou seja, o teórico, o prático e o estético, os quais dizem respeito, por sua vez, do ponto de vista arquitetônico, respectivamente, às suas três Críticas: a “Crítica da Razão Pura”, a "Crítica da Razão Prática” e a "Crítica do Juízo”. Obviamente que, no âmbito de suas aulas "Sobre a pedagogia", ele faz apenas breve referência a estes três diferentes usos da razão humana, sem problematizar, por exemplo, o emprego prático (moral) da mesma e como nele se acomodaria o uso formativo da razão. Independentemente disso, com esforço interpretativo, podemos ter uma ideia aproximada de seu projeto pedagógico para o amplo cultivo das capacidades humanas.

No caso específico do cultivo do entendimento (Verstand), aparecem, do ponto de vista formativo (pedagógico), importantes indicações. O entendimento, sendo a capacidade cognitiva por excelência, isto é, a fonte geradora do conhecimento científico, precisa ser formado de maneira vivaz e não meramente mecânica. O que Kant tem em mente com isso? Pensa que o bom uso do entendimento é aquele que auxilia no desenvolvimento da própria capacidade de julgar. De nada adianta seguir mecanicamente as regras, pois é preciso compreender seu significado e, inclusive, deixar espaço aberto, livre, para a própria criação de regras, uma vez que esta capacidade criativa é indispensável para o exercício futuro da cidadania democrática. Por isso, do ponto de vista formativo, é importante que o educando tenha consciência da regra que segue, o que somente consegue fazê-lo quando a aprendizagem está colada à sua 
experiência. Vê-se aqui que Kant pensa, bem ao estilo rousseauniano, a educação infantil como educação pelas coisas, devendo ela estar baseada no jogo e na brincadeira. É precisamente no âmbito da educação infantil que, primeiramente, se deve fortalecer o corpo e refinar os sentidos da criança e só paulatinamente se concentrar no cultivo propriamente cognitivo, mediante o qual a criança começa a fazer uso de suas capacidades intelectuais. De outra parte, mesmo no âmbito do uso estritamente cognitivo da inteligência humana, cujo foco recai sobre o cultivo de capacidades especificamente científicas, com visível propensão tecnológica, a educação não deve concentrar-se exclusivamente na formação profissional do educando, visando apenas sua rentabilidade futura. Ao contrário, Kant reivindica o uso ampliado do entendimento, direcionando-o claramente para o cultivo da capacidade de julgar por conta própria e o faz porque sabe que o cultivo do pensamento autônomo é peça chave na formação do futuro cidadão. Pois, como sabemos, a regra de ouro do esclarecimento (Aufklärung) moderno, o qual, aliás, preserva impressionante atualidade, diz que quem não tem a capacidade de discernimento próprio, torna-se imediatamente refém de forças externas. E, ao contrário, ter a coragem de servir-se de seu próprio entendimento, ou seja, da capacidade de julgar por si mesmo, é a condição primeira da dignidade humana.

Contudo, o entendimento no sentido ampliado refere-se à própria razão (Vernunft) como capacidade das capacidades, que abarca em si tanto o entendimento (Verstand), no sentido acima referido, quanto a imaginação (Einbildungskraft). No âmbito da filosofia teórica kantiana, precisamente na "Crítica da Razão Pura", a razão, como sede das ideias, desempenha papel fundamental para assegurar a passagem do emprego teórico para o emprego prático da razão pura. Posteriormente, nos escritos propriamente morais, a razão transforma-se, mais e mais, na fonte de justificação do agir moral, ocupando-se diretamente com sua fundamentação. Este sentido filosófico, prático, da Vernunft é mantido no âmbito das aulas "Sobre a pedagogia", mas assume aí nitidamente dimensão formativa, visando a própria educação moral.

Neste âmbito formativo, a razão tem a ver com o método mais adequado para a construção do caráter, exigindo, por isso, a inserção progressiva da criança no universo das leis morais. A esse respeito, Kant é categórico: não se deve inculcar princípios morais no educando, pois de nada adiantaria. Ora, se na educação moral o método catequético não funciona, então, que outro método deveria ser utilizado? O sugerido é o método socrático, sobretudo, porque ele possui a grande vantagem pedagógica de propiciar, por meio do espírito inquiridor, que o educando, com o auxílio do educador, forme-se moralmente a si mesmo. Ou seja, quando se trata da educação moral, faz-se necessário o cultivo intenso da capacidade de autodeterminação, 
a qual não é outra coisa senão a capacidade que o sujeito tem de dar a si mesmo a lei (Selbstgeseztgebung) e, com isso, determinar moralmente sua própria vontade (Wille).

Por fim, Kant considera a imaginação também como uma das capacidades humanas superiores. Ela refere-se diretamente aos sentimentos do prazer e desprazer, tratando, portanto, da formação do gosto (Geschmack). A tese filosófica de fundo, que ganha no contexto das aulas "Sobre a pedagogia" sentido formativo preciso, reza que tanto a capacidade cognoscitiva quanto a prático-moral enlaçam-se com a capacidade estética, motivo pelo qual, entendimento e razão precisam da força da imaginação. Nesse sentido, a capacidade de fantasiar torna-se a mola propulsora das outras capacidades humanas superiores e, sendo assim, a educação do gosto ocupa lugar especial no âmbito da educação moral. Kant tem como alvo o problema, já enfrentado nos séculos XVII (John Locke) e XVIII (Jean-Jacques Rousseau), do gosto afetado (zarter Geschmack) e do quanto ele pode conduzir à conduta viciada do ser humano (criança). O gosto afetado, vindo normalmente associado ao gosto pela facilidade, torna-se a maior fonte viciosa do caráter; por isso, os adultos precisam evitar que as crianças permaneçam desocupadas por muito tempo, tendo inclusive de inseri-las no trabalho, compreendido aqui principalmente como estudo diário orientado detalhadamente por um plano. Ora, se a capacidade de imaginação diz respeito ao cultivo do gosto, no âmbito da educação infantil, "o primeiro gosto a ser cultivado será o dos sentidos, sobretudo o da vista e, por último, o gosto das ideias" (KANT, 1998, p. 734). Nesse caso, o que vem por último, ou seja, o cultivo do gosto das ideias, que descortina ao educando o universo do mundo moral e estético, torna-se central, porque no âmbito da educação moral a tarefa da capacidade imaginativa consiste em contribuir para formar um "gosto justo" ("richtiger Geschmack"). O direcionamento do gosto estético para a formação do gosto justo é mais uma prova do quanto a ideia de educação pública está alicerçada no desenvolvimento de todas as capacidades humanas, concebendo tal desenvolvimento equilibrado como condição primeira da formação do futuro cidadão. É o entrelaçamento entre estas duas dimensões da formação humana, do gosto estético e do gosto moral (justo), que possibilita a ideia de a educação pública ir muito além da mera formação profissional visando a renda futura do educando. Ou seja, decisivo para isto não é obviamente focar só no cultivo da capacidade de conhecimento, mas sim no cultivo simultâneo do gosto moral e do gosto estético.

O cultivo destas três grandes capacidades superiores, profundamente entrelaçadas entre si, conduz à moralização humana. Mas em que consiste, mais precisamente, tal moralização? Ela tem a ver diretamente com a formação do caráter enquanto domínio do querer, ou seja, como autogoverno das paixões, conquistado mediante a consciência e prática do dever (Sollen). Dever não significa aqui, obviamente, a mera obrigação formal imposta de fora, mas sim, 
quando interpretado no âmbito do cultivo das capacidades humanas, o exercício permanente que o ser humano (educando) faz consigo mesmo, com os outros e com o próprio mundo. Nesse contexto, Kant atribui ao dever dupla dimensão: uma que abarca especificamente a relação do educando consigo mesmo, na qual ele é formado para orientar-se pela ideia de dignidade interior ou autoestima, tomada como mola propulsora do valor público a ser buscado; e outra referente à dimensão do dever que se põe na relação do educando com os outros, cujo foco é o direito de humanidade. Portanto, como cultivo das capacidades humanas, a educação moral, que sustenta a ideia de educação pública, nada mais é do que uma ética das virtudes, ou seja, uma força que o ser humano exerce sobre si mesmo visando sua própria dignidade e a dignidade dos outros.

Em síntese, as aulas "Sobre a pedagogia" concedem prioridade à educação pública sobre a educação doméstica, tomando aquela como base de sustentação cultural e moral da democracia republicana. Tal sustentação ocorre, do ponto de vista filosófico formativo, por meio do cultivo das capacidades humanas, especialmente do entendimento, da razão e da imaginação. $\mathrm{O}$ trabalho formativo cuidadoso destas capacidades junto à criança é indispensável para que ela adquira, aos poucos, a capacidade de julgar por conta própria, alcançando o nível de autodeterminação moral e política requerido para sua participação democrática na esfera pública.

\section{Considerações conclusivas}

Intentamos mostrar, na primeira parte do ensaio, a ruptura entre filosofia política e pedagogia, entre teoria da democracia e teoria da formação humana e o quanto tal ruptura dificultou a reflexão sobre o crescimento mundial do neoconservadorismo. Na segundo parte, considerando o diagnóstico de que o avanço da perspectiva neoconservadora provoca a destruição da educação pública e considerando o quanto isso obstaculiza a consolidação cultural e moral da democracia, procuramos reconstruir alguns traços gerais da educação republicana esboçada por Kant em suas aulas "Sobre a pedagogia”. Concluímos que a ideia kantiana de educação pública, focada no cultivo de todas as capacidades humanas, é o aspecto nuclear da formação do futuro cidadão, devendo, por isso, ser também a tarefa primeira da escola pública.

A distância que nos separa do contexto histórico e social de Kant permite visualizar hoje melhor os limites nos quais se insere sua própria ideia de educação pública. O primeiro limite é interno e diz respeito ao tom genérico e ao mesmo tempo superficial com o qual ele compreende a inteligência humana nas aulas "Sobre a Pedagogia". Embora sua preocupação 
seja aí nitidamente pedagógica, certamente ele teria aprofundado ainda mais sua ideia de educação moral, assentada no cultivo das capacidades humanas, se tivesse levado em conta, com mais profundidade, os resultados de suas próprias investigações filosóficas, empreendidas principalmente no âmbito das três Críticas. De outra parte, se consideramos as pesquisas sobre o cérebro e a mente humana desenvolvidas depois de Kant, tanto pela filosofia quanto pela psicologia e pelas neurociências, podemos perceber que falta muito em termos de detalhamento e precisão das três grandes capacidades humanas, arroladas pelo filósofo de Königsberg. Sendo assim, permanece a dúvida sobre o quanto o grau elevado de abrangência atribuído às três capacidades superiores consegue apreender, efetivamente, da inteligência humana e como poderia se traduzir, do ponto de vista do currículo escolar, em programa de formação do educando.

Ao conhecimento impreciso destas grandes capacidades humanas - e este é o segundo limite que gostaríamos de indicar - corresponde também o problema da condição infantil e dos métodos apropriados de educação da criança. Kant diagnostica acertadamente, inspirado principalmente em Rousseau, a tensão inerente à condição humana, entre egoísmo e cooperação solidária. Contudo, por dar atenção excessiva à dimensão racional do ser humano, possui dificuldades de perceber o papel que os afetos desempenham na formação do caráter infantil e o quanto são indispensáveis para pensar a educação moral da criança, ou seja, a conquista penosa de seu autogoverno em relação aos vícios que seu querer inflamado impõe. Deste modo, a descrição que Kant oferece do fortalecimento do corpo e do refinamento dos sentidos da criança permanece ainda muito lacunar e genérica. Talvez seja por isso que não consegue formular, em "Sobre a pedagogia", um programa mais desenvolvido de educação estética e artística do educando, fato esse que auxiliaria ainda mais para mostrar o quanto o cultivo das humanidades no âmbito da educação escolar é indispensável à formação do futuro cidadão.

Por último, o terceiro limite a ser notado, também observado por Axel Honneth (2013), refere-se ao fato de que a ideia de público em Kant não é tão abrangente quanto ele imaginava ter sido. Seu cosmopolitismo é dirigido prioritariamente para o ser humano branco, do sexo masculino e em perfeitas condições físicas e mentais. Por isso, não trata especificamente do negro, da mulher e das crianças portadoras de algum tipo de deficiência especial. Também não põe a si mesmo o problema de ter que pensar a educação pública, moral e política, no âmbito de um modelo social, como o brasileiro, no qual predomina a presença significativa de educandos (crianças) abaixo do grau de pobreza, passando fome e não tendo satisfeitas muitas outras de suas necessidades básicas. Neste sentido, a mesma objeção que Martha Nussbaum (2013) dirige ao liberalismo político de John Rawls também serve, mutatis mutandis, ao 
pensamento de Kant, exigindo que o projeto de educação pública, voltado para a formação da cidadania democrática, inclua prioritariamente problemas de igualdade social, de gênero e de portadores de deficiência física e mental.

Contudo, tais críticas a Kant não enfraquecem a atualidade de alguns aspectos de sua ideia de educação pública. Gostaríamos, a título de conclusão, referir brevemente três destes aspectos. Em primeiro lugar, considerando o contexto político e educacional que nós encontramos atualmente, a defesa enfática de Kant da educação pública serve de referência para destacar sua importância para a formação cultural das futuras gerações. Pois, como afirmou categoricamente Adorno (1971), quase dois séculos depois de Kant, uma educação que queira somente profissionalizar termina exatamente por não profissionalizar. Isso significa dizer que a educação focada no cultivo de todas as capacidades humanas, quando feita amplamente, tem melhores condições de realização, inclusive do próprio objetivo restrito da profissionalização, simplesmente porque uma inteligência versátil, movida por diferentes perspectivas, como a estética e a moral, torna ainda mais abrangente e eficiente o próprio olhar profissional: estimulado a fazer uso de todas as suas capacidades em seu processo de formação, o educando está sendo preparado para analisar os problemas sob diferentes perspectivas e, por conseguinte, estará mais apto a encontrar soluções eficazes. Isso cria melhores condições para a formação de um futuro profissional, com maneira alargada de pensar, ao qual se possa integrar a consciência de cidadania democrática.

Em segundo lugar, seu foco no cultivo das capacidades humanas nos permite perceber a estreiteza da educação que se volta para a formação profissional, visando exclusivamente à renda futura e mostra o quanto isso compromete a formação cultural e moral, indispensável à consolidação de sociedades democráticas. Como contraponto crítico a tal estreiteza, a proposta do amplo cultivo de todas as capacidades humanas, abrangendo esquematicamente a dimensão cognitiva, moral e estética, oferece a ideia ampla de ser humano, mais apropriada para o contexto de sociedades plurais e complexas. Torna-se uma maneira mais inteligente e humana de trabalhar os conflitos e dramas tanto individuais como sociais.

Por fim, em terceiro lugar, nas aulas "Sobre a pedagogia", Kant desenvolve uma intuição genuína, herdada de Rousseau, de que a vitalidade da república democrática depende da formação cultural e moral de todos os seres humanos, a qual precisa iniciar já na mais tenra idade. Nesse sentido, propiciar às crianças experiências de convivência solidária é importante para que elas possam enfrentar criticamente sua própria disposição individualista inflamada, que é um dos principais obstáculos à formação do futuro cidadão. Por isso, deve-se colocar à disposição dos educandos oportunidades pedagógicas para que possam cultivar entre si 
experiências sociais cooperativas. Ora, oportunizar isso continua sendo, ainda hoje, tarefa central da educação pública, como procuramos argumentar ao longo deste ensaio.

\section{Referências}

ADORNO, Theodor. Erziehung zur Mündigkeit. Frankfurt am Main: Suhrkamp, 1971.

BÖCKENFÖRDE, Ernst-Wolfgang. Recht, Staat, Freiheit. Frankfurt am Main: Suhrkamp, 2006.

BÜTTEMEYER, Wilhelm; MÖLLER, Bernhard (Hrsg.). Der Positivismusstreit in der deutschen Erziehungswissenschaft. München: Wilhelm Fink Verlag, 1979.

DALBOSCO, Claudio Almir. Condição humana e educação natural em Jean-Jacques Rousseau. São Paulo: Edições Loyola, 2016.

FORST, Rainer. Contextos da justiça: filosofia política para além do liberalismo e comunitarismo. São Paulo: Boitempo Editorial, 2010.

HABERMAS, Jürgen. Entre naturalismo e religião: estudos filosóficos. Rio de Janeiro: Tempo Brasileiro, 2007.

HONNETH, Axel. Educação e esfera pública democrática. Um capítulo negligenciado da filosofia política. Revista Civitas, Porto Alegre, v. 13, n. 3, p. 544-562, 2013.

KANT, Immanuel. Schriften zur Anthropologie, Geschichtsphilosophie, Politik und Pädagogik. Band VI. Darmstadt: Wissenschaftliche Buchgesellschaft, 1998.

NUSSBAUM, Martha. Fronteiras da justiça: deficiência, nacionalidade, pertencimento à espécie. São Paulo: Martins Fontes, 2013.

NUSSBAUM, Martha. Sem fins lucrativos: por que a democracia precisa das humanidades. São Paulo: Martins Fontes, 2017.

PLATÃO. A república. Lisboa: Fundação Calouste Gulbenkian, 1987.

ROUSSEAU, Jean-Jacques. Emílio ou da educação. Rio de Janeiro: Bertrand Brasil, 1992.

SCHMIED-KOWARZIK, Wolfdietrich. Filosofia prática e pedagogia. In: DALBOSCO, C. A. (org.). Filosofia prática e pedagogia. Passo Fundo: Editora UPF, 2003. p. 60-83.

TENORTH, Heinz-Elmar. Geschichte der Erziehung: Einführung in die Grundzüge ihrer neuzeitlichen Entwicklung. Weinheim/München: Juventa, 2010.

VORLÄNDER, Karl. Immanuel Kant. Der Mann und das Werk. Wiesbaden: Fourier Verlag, 2003. 